\title{
DESVENDANDO O SIGNIFICADO DE EXPERIÊNCIAS CLÍNICAS INICIAIS DE ESTUDANTES DE GRADUAÇÃO EM ENFERMAGEM ${ }^{1}$
}

\author{
UNVEILING THE SIGNIFICANCE OF INITIAL CLINICAL EXPERIENCES FOR \\ UNDERGRADUATE NURSING STUDENTS \\ DESVENDANDO EL SIGNIFICADO DE EXPERIENCIAS CLÍNICAS \\ INICIALES DE ESTUDIANTES DEL CURSO DE ENFERMERÍA
}

Patrícia Moita Garcia Kawakame ${ }^{2}$ Tatiana Matos Garcia ${ }^{3}$

\begin{abstract}
RESUMO: Este estudo pretendeu compreender o significado de vir a ser aluno de graduação em enfermagem em sua primeira experiência clínica em instituição hospitalar a partir do mundo- vida dos próprios alunos. Um estudo fenomenológico foi aplicado para explorar a experiência vivida de 17 estudantes de enfermagem que revelaram através de seus discursos a existência de um choque de realidade, produzido devido a condições precárias de trabalho, permeado por sentimentos tais como pena dos pacientes, medo e insegurança, fazendo emergir desejo de fuga, proporcionando uma experiência divergente qualificada como horrivel para alguns e agradável para outros, onde o papel da supervisora aparece como ponto de apoio. Acreditamos que este estudo possa contribuir como subsídios para uma reflexão e possivel intervenção dos enfermeiros educadores, bem como proporcionar uma relação mais autêntica entre aluno e professor.
\end{abstract}

PALAVRAS-CHAVE: estudante de enfermagem, experiências clínicas iniciais em instituição hospitalar,fenomenologia

\section{INTRODUÇÃO}

O interesse em realizar este estudo surgiu a partir de nossas vivências, na área de Enfermagem, após detectarmos comportamentos de ansiedade e medo nos alunos, em experiências clínicas iniciais em instituição hospitalar.

Visando compreender o fenômeno a partir de experiências vividas pelos alunos, optamos por uma abordagem qualitativa através da fenomenologia, mais especificamente o fenômeno situado e buscamos na revisão de literatura o embasamento teórico necessário para o desenvolvimento desta pesquisa.

Ângelo (1989, p.115) em sua tese de doutorado concluiu que o início da aprendizagem prática de enfermagem para as alunas tratava-se de uma experiência difícil e frustrante, sendo que a autora identificou as conclusões referentes a sua pesquisa a um processo, o qual atribuiu o nome de "VIVENDO UMA PROVA DE FOGO".

Segundo Beck (1993, p.489) estudantes de enfermagem têm revelado alguns aspectos geradores de ansiedade em suas experiências clínicas iniciais e para ajudar estes alunos a escola, primeiramente, tem que compreender o significado desta experiência para eles.

\footnotetext{
1 Prêmio Marina de Andrade Rezende, $3^{\circ}$ lugar, $52^{\circ} \mathrm{CBE}$.

${ }^{2}$ Enfermeira professora da Fundação Educacional de Fernandópolis - FEF e mestranda da Escola de Enfermagem da Universidade de São Paulo - EEUSP.

${ }^{3}$ Graduanda do Curso de Enfermagem da Fundação Educacional de Fernandópolis - FEF.
} 
Schmarczek (1984, p.321) identificou que em situações de estágio os alunos de enfermagem apresentam maior ansiedade que em situações de aprendizagem em sala de aula e segundo Sadala (1994, p.33) os estudantes associam a ansiedade e o estresse à sua inexperiência, ao despreparo em lidar com situações críticas na prática e à interferência das horas exigidas para estudos teóricos.

Outros autores se preocuparam em estudar o comportamento dos estudantes de enfermagem: Guz (1983, p.88) define ansiedade como uma reação onde grande número de seres vivos apresenta quando há uma ameaça efetiva ou imaginária à sua integridade ou à sua própria existência;Jorge (1996, p. 146 ) escreve que os alunos superam as dificuldades, buscando conhecimento prático com os colegas que já passaram por situações semelhantes, bem como buscando conhecimentos teóricos. Sadala (1994, p.33) afirma que os alunos devem desenvolver mecanismos mais adequados para lidarem com a própria ansiedade, contando com a ajuda dos docentes e profissionais envolvidos nas atividades de estágio; Ângelo (1989, p.117) detectou a necessidade de implementação de estruturas de apoio na Escola para alunos de graduação de enfermagem, principalmente durante o início da experiência clínica e Carvalho et al. (1999, p.255) ressalta que o primeiro estágio hospitalar do acadêmico de enfermagem pode ser a chave que abrirá ou fechará a porta de uma carreira, e que a figura do docente se destaca de forma significativa , por ser ele no grupo o mais maduro e o mais preparado tecnicamente, além de ter que ser o mais sensato. Sendo que a sua atitude e seu agir será o ponto de equilíbrio nas relações que o aluno desenvolverá no seu primeiro estágio hospitalar.

\section{TRAJETÓRIA METODOLÓGICA}

A abordagem utilizada neste estudo foi a Fenomenologia através da análise da estrutura do fenômeno situado. A fenomenologia foi descrita por Edmund Husserl, na Alemanha, como uma altemativa na busca do conhecimento, considerando o método experimental pouco adequado para tratar as questões do homem e de seu mundo vivido.

Nessa abordagem compreensiva a partir da reflexão de experiências vividas por alunos de graduação de Enfermagem e tendo em vista que a fenomenologia visa compreender o existencial , valorizando o conteúdo da experiência em si, vemos neste método uma possibilidade de ir ao encontro do fenômeno.

Vale ressaltar que Heidegger (1995, p.11) faz uma redefinição da Fenomenologia, caracterizando-a como um método que não procura o quê do objeto de estudo, mas o como se mostra a partir de si mesmo, como experiência o mundo. Para este fenomenólogo o Ser-nomundo relaciona-se com três níveis, o ambiente, ou o mundo ao redor, as relações ou o mundo com os semelhantes e o interior, ou o mundo consigo mesmo, sendo que estes níveis dão forma à existência do homem.

Portanto, pretendemos através da fenomenologia heideggeriana, ver o homem através dele próprio, visando compreender aquele que se adentra em uma instituição hospitalar para o desenvolvimento de uma prática profissional , a fim de desvelar esta experiência vivenciada pelo aluno de graduação de enfermagem.

\section{CONSTITUIÇÃO DOS DADOS}

Os dados desta pesquisa estão apresentados através das descrições de relatos de estudantes de graduação de enfermagem que estão vivenciando as suas primeiras experiências clínicas em instituição hospitalar.

Com o propósito de buscar um contexto onde o fenômeno pudesse ser inquerido , escolhemos uma Unidade de Clínica Médica de uma instituição hospitalar de Fernandópolis, que corresponde ao primeiro campo de aulas práticas, em instituição hospitalar, de alunos do $2^{\circ}$ 
ano do Curso de Graduação em Enfermagem da Fundação Educacional de Fernandópolis (FEF).

Os dados foram coletados através de entrevista individual e após assinarem o termo de consentimento pós-informado e concordarem em participar desta pesquisa. Cabe esclarecer que os alunos foram informados em relação ao anonimato que será mantido e que poderiam desistir de participar a qualquer momento, sem qualquer prejuízo das suas atividades escolares.

Os discursos dos sujeitos foram gravados e transcritos na íntegra, e emergiram através da seguinte questão norteadora: Como é para você este primeiro contato com o campo de aulas práticas em instituições hospitalares?

\section{ANÁLISE DOS DADOS}

Os dados foram analisados através dos discursos dos sujeitos de acordo com a análise ideográfica e nomotética, para as quais nos embasamos em Martins e Bicudo (1989, p.101). A análise ideográfica trata-se da análise da ideologia que permeia as descrições ingênuas ou discursos dos sujeitos. É uma análise individualizada das descrições, onde podemos identificar os seguintes momentos: leitura das descrições do princípio ao fim, quantas vezes for necessário, para que o pesquisador possa familiarizar-se com ela; discriminação das unidades de significados, tendo em vista o fenômeno que esta sendo pesquisado; transformação das expressões cotidianas do sujeito em uma linguagem adequada; síntese das unidades de significado, transformandoas em uma descrição consistente referente às experiências dos sujeitos.

$\mathrm{Na}$ análise nomotética o pesquisador relê as estruturas individuais e determina quais aspectos que manifestam uma verdade geral e qual não o fazem. Assim, as convergências passam a caracterizar a estrutura do fenômeno e as divergências disposições individuais que fazem com que haja reação muito pessoal à ação dos agentes externos.

Após as análises, desvendamos através das convergências, divergências e idiossincrasias a essência dos significados atribuídos pelos alunos de graduação de enfermagem a experiência clínica inicial em instituição hospitalar.

\section{Análise Ideográfica}

Foram utilizados 17 discursos de alunos de graduação de enfermagem, que foram transcritos na íntegra, buscando manter a sua fala originária, posteriormente foram extraídas as unidades de significados, que foram enumeradas no próprio discurso e em seguida interpretadas, transformando em conteúdo mais compreensivo, mostrando estruturas que pareciam ocultas, como exemplifico.

\section{DISCURSO X}

O primeiro contato para mim com o ambiente hospitalar foi um choque, porque eu imaginava uma coisa e foi diferente daquilo, 1 mas eu me identifiquei muito com o local 2. No primeiro dia estranhei um pouco. 3 Mas, no restante dos dias, eu me identifiquei muito apesar de ser um local precário como a saúde no Brasil 4, ela é precária. Os materiais são faltosos e a estrutura da unidade também não ajuda o nosso contato melhor com o cliente 5. 
QUADRO 1 - UNIDADES DE SIGNIFICADO

\begin{tabular}{|c|c|c|c|}
\hline Fala da pessoa & $\begin{array}{l}\text { Linguagem da } \\
\text { Pesquisadora }\end{array}$ & $\begin{array}{l}\text { Unidades de } \\
\text { Significado } \\
\text { Convergidas }\end{array}$ & $\begin{array}{l}\text { Números de } \\
\text { Unidades } \\
\text { Convergentes }\end{array}$ \\
\hline $\begin{array}{l}\text { 1. Foi um choque, porque eu } \\
\text { imaginava uma coisa e foi } \\
\text { diferente daquilo. }\end{array}$ & $\begin{array}{l}\text { 1. Aluna ficou } \\
\text { chocada pela } \\
\text { realidade diferente do } \\
\text { que esperava }\end{array}$ & $\begin{array}{l}\text { 1. Aluna ficou chocada pela } \\
\text { realidade diferente do que } \\
\text { esperava. }\end{array}$ & 1. 3 \\
\hline $\begin{array}{l}\text { 2. Mas eu me identifiquei muito } \\
\text { com o local. }\end{array}$ & $\begin{array}{l}\text { 2. A aluna se } \\
\text { identificou muito com } \\
\text { o local }\end{array}$ & $\begin{array}{l}\text { 2. A aluna se identificou } \\
\text { muito com o local. }\end{array}$ & 2,4 \\
\hline $\begin{array}{l}\text { 3. No primeiro dia estranhei um } \\
\text { pouco. }\end{array}$ & $\begin{array}{l}\text { 3. A aluna estranhou a } \\
\text { realidade do local no } \\
\text { primeiro dia }\end{array}$ & & \\
\hline $\begin{array}{l}\text { 4. Mas, no restante dos dias, } \\
\text { eu me identifiquei muito, apesar } \\
\text { de ser um local precário como } \\
\text { a saúde no Brasil }\end{array}$ & $\begin{array}{l}\text { 4. Aluno se adaptou } \\
\text { e se identificou com o } \\
\text { local no decorrer das } \\
\text { aulas práticas, apesar } \\
\text { de ser um local em } \\
\text { condiçōes precárias }\end{array}$ & & \\
\hline $\begin{array}{l}\text { 5. Os materiais sâo faltosos e a } \\
\text { estrutura da unidade tambem } \\
\text { não ajuda o nosso contato } \\
\text { melhor com o cliente. }\end{array}$ & $\begin{array}{l}5.0 \text { aluno considera } \\
\text { que a falta de } \\
\text { estrutura do local } \\
\text { prejudica a } \\
\text { assistência prestada } \\
\text { ao cliente: }\end{array}$ & $\begin{array}{l}5 \text { O aluno considera } \\
\text { que a falta de } \\
\text { estrutura do local } \\
\text { prejudica a } \\
\text { assistência prestada } \\
\text { ao cliente }\end{array}$ & 5 \\
\hline
\end{tabular}

\section{Análise nomotética}

A seguir apresentamos a análise nomotética, onde buscamos as generalidades que configuram os significados que os alunos de graduação em enfermagem atribuem à experiência clínica inicial em instituição hospitalar.

Nos embasamos no modelo elaborado por Lima (1991, p.62) para a elaboração do quadro de análise nomotética. Inicialmente agrupamos em categorias amplificadas as unidades de significados convergidas originadas da análise ideográfica.

\section{COMPREENDENDO O SER ALUNO DE GRADUAÇÃO DE ENFERMAGEM EM EXPERIÊNCIA CLIINICA INICIAL EM INSTIUIÇÄO HOSPITALAR}

As convergências nos discursos dos alunos revelaram um choque de realidade , conforme evidenciado nos seguintes discursos: 
Eu tive um choque porque era uma situação muito precária (Discurso I)

Foi um impacto porque é uma realidade muito precária... (Discurso VII)

Foi um choque muito grande para mim , pois fugiu totalmente da realidade e do que eu tinha aprendido em sala de aula (Discurso III)

Também emergiu das falas dos alunos uma qualificação da experiência clínica inicial em hospital, apesar da maioria dos discursos dos alunos serem convergentes ao considerarem uma experiência boa ou agradável, evidenciou-se algumas concepções divergentes, uma vez que alguns alunos classificaram as experiências como horriveis, explicitadas em algumas falas:

Foi uma experiência muito boa para mim, com certeza (Discurso III)

Foi uma boa experiência(Discurso XII)

Eu achei muito horrivel (Discurso XV)

Nossa horrivel! eu odiei, odiei!(Discurso XVII)

A insegurança e o medo emergem como elemento significativo na fala dos alunos:

Ao primeiro contato me senti um pouco inseguro (Discurso IV)

Eu senti um pouco de medo e insegurança... (Discurso XII)

Eu fiquei morrendo de medo...(Discurso XV)

A experiência profissional adquirida, por alunos que já trabalham na profissão aparece como motivo de encarar com normalidade a realidade do local, apesar de terem a conscientização da situação precária de trabalho, conforme falas:

Eu já trabalhei em hospital filantrópico com a mesma realidade aonde você tem que improvisar muita das coisas existentes ali... (Discurso IV)

...foi normal, pois já trabalho em serviço hospitalar (Discurso VIII)

A identificação com o local também aparece como elemento convergente nas falas dos entrevistados:

É um lugar que eu me identifiquei... (Discurso V)

Eu acho que é o lugar que eu me encontro...(Discurso IX)

...no primeiro dia estranhei um pouco, mas no restante dos dias eu me identifiquei muito(Discurso $\mathrm{X}$ )

A falta de estrutura do local como aspecto negativo da experiência clínica inicial também emerge como elemento importante nas convergências das falas dos alunos:

...muito deprimente porque as salas onde os clientes ficam são muito apertadas, falta de higiene, a situação é muito precária mesmo...(Discurso VI)

Acho que tem algumas falhas no setor hospitalar devido à falta de materiais porque você demora muito para desenvolver uma técnica...(Discurso VIII)

O contato direto com os pacientes proporcionando uma experiência agradável emerge também nas falas dos sujeitos:

...é bom que você tem contato direto com o paciente... (Discurso VI) 
...Foi bom que a gente aprende e entra em contato com os pacientes (Discurso XIV)

... as pessoas lá são muito carentes acho que precisam muito de carinho e apoio, eu achei legal...(Discurso IX)

A presença da supervisora trazendo segurança para o aluno emerge no seguinte discurso:

Eu estive seguro, pois contava com uma professora responsável. (Discurso XIII)

A associação da teoria com a prática emerge na fala deste sujeito:

...permitiu nos a integração dos conceitos teóricos assimilados com a realização da própria prática(Discurso XIII)

Também emerge nas falas dos alunos sentimento de fuga como elemento importante, explicitado nas seguintes falas:

Eu senti vontade de ir embora, mesmo!(Discurso XV)

Vontade de ir embora, de não voltar... ( Discurso XVI)

Também emergiu nas falas dos alunos sentimento de pena dos pacientes no processo de cuidar, conforme aparece nas seguintes falas:

...um sentimento de dó pelas pessoas ...(Discurso XVI)

Muita dó, muita, muita, muita dó(Discurso XVII)

Acreditamos ter desvelado o significado da experiência clínica inicial em instituição hospitalar para os alunos de graduação em Enfermagem. E após refletirmos sobre elementos importantes da experiência clínica inicial em hospital sob a visão de mundo dos próprios alunos, elaboramos algumas considerações.

\section{HORIZONTES DE UM PENSAR A CERCA DOS SIGNIFICADOS DA EXPERIÊNCIA CLÍNICA INICIAL EM INSTITUIÇÃO HOSPITALAR PARA ALUNOS DE GRADUAÇÃO EM ENFERMAGEM}

De acordo com as convergências dos discursos dos alunos a experiência clínica inicial em instituição hospitalar emerge como algo chocante para aqueles que a vivenciam devido mais especificamente a um choque de realidade, considerando que a realidade dos mesmos parece ser bastante diferente, tanto em relação ao que aprenderam na escola quanto aos seus estilos de vida, daquela encontrada na unidade clínica de internação de um hospital filantrópico, onde se encontram pacientes internados pelo convênio especial do Sistema Único de Saúde SUS.

Quanto à qualificação da experiência vivenciada, emergiram divergências, sendo que alguns consideraram agradável ou boa, porém para outros a experiência foi horrível. Acreditamos que este fato tenha ocorrido devido ao choque de realidade ter sido muito intenso, para alguns alunos, ao ponto de mantê-los alienados ao restante do contexto das situações vivenciadas. Parece, também, que este choque de realidade, gerou uma situação interpretada como ameaçadora para estes alunos, o que contribuiu para emergir sentimentos de fuga.

Porém, outros apesar de também se chocarem com a realidade, conseguem obter um 
enfrentamento adequado, proporcionando uma adaptação ao local, sendo capazes de aproveitar as oportunidades oferecidas, na tentativa de associar a teoria à prática, bem como aprimorar o relacionamento interpessoal com os pacientes, conseguindo estabelecer relação de ajuda, que permeia todo o processo de cuidar. Sendo que após este período de adaptação os alunos são capazes até mesmo de se identificar com o local e perceberem a experiência clínica inicial como agradável e importante.

Infelizmente a falta de estrutura e as condições precárias de trabalho referentes ao local, que convergiram nas falas dos alunos, influiu, de maneira bastante negativa no vivenciar da primeira experiência clínica em hospital. Lembrando que a experiência profissional prévia na área de enfermagem, contribuiu no sentido de minimizar o choque de realidade, ocorrido devido à falta de estrutura e condições ideais de trabalho.

Vale ressaltar que o medo e a insegurança permeiam a experiência clínica inicial dos alunos e que a presença da supervisora aparece trazendo segurança para os mesmos.

Portanto, acreditamos que este estudo possa acrescentar para uma compreensão do que é vir a ser aluno de graduação em enfermagem em sua primeira experiência clínica inicial em hospital, servindo como subsídios para uma reflexão e possível intervenção dos enfermeiros educadores em atividade de supervisão em instituições hospitalares.

\begin{abstract}
This phenomenological study intended to understand the meaning of coming to be a nursing student, during the first clinical trial in a hospital, exploring such experience from the student's perspective. The study sample was comprised of 17 undergraduate nursing students which revealed through their narratives the experience of a reality shock due to precarious work conditions, permeated by feelings such as sorrow for the patients, fear and insecurity, leading to a desire to escape, resulting in divergent experiences, qualified as horrible for some and pleasant for others, whereas the role of the supervisor appears as supportive. The authors consider that this study can contribute to further reflection and possible intervention on part of nursing instructors, as well as to foster a more authentic relationship between student and teacher.
\end{abstract}

KEYWORDS: nursing student, hospital clinical experiences, phenomenology

RESUMEN: El estudio pretendió comprender el significado de venir a ser un alumno del curso de enfermería en su primera experiencia clínica en institución hospitalar a partir del mundo-vida de los propios alumnos. Un estudio fenomenológico fue aplicado para explorar la vivencia de 17 estudiantes que revelaron a través de sus discursos la existencia de un choque de realidad, debido a las condiciones precarias de trabajo. En el discurso expresaban también sentimientos, tales como pena por los pacientes, miedo e inseguridad, haciendo emergir un deseo de huida y proporcionándoles una experiencia divergente calificada como horrible para algunos y agradable para otros. El papel de la supervisora aparece como ahí como punto de apoyo. Creemos que este estudio pueda contribuir como subsidio para una reflexión y posible intervención de los enfermeros educadores, además de proporcionar una relación más auténtica entre alumno y profesor

PALABRAS CLAVE: estudiante de enfermería, experiencias clínicas iniciales en institución hospitalar, fenomenología

\title{
REFERÊNCIAS BIBLIOGRÁFICAS
}

ANGELO, Margareth. Vivendo uma prova de fogo : as experiências iniciais da aluna de enfermagem. 1989.133p. Tese ( Doutorado em Psicologia) - Instituto de Psicologia, Universidade de São Paulo, São Paulo. 
BECK, Cheryl Tatano. Nursing students' initial clinical experience: a phenomenological study J. Nurs. Stud, Great Britain, v.30, n.6, p.489-497, jun. 1993.

CARVALHO, Maria Dalva de Barros et al. Expectativas dos alunos de enfermagem frente ao primeiro estágio em hospital. Rev.Esc.Enf.USP, São Paulo, v.33, n.2, p.200-6, jun. 1999.

GUZ, Isaac. Ansiedade conceituação e tratamento . ARS CVRANDI, p. 88-94, abr. 1983.

HEIDEGGER, M. Ser e Tempo: Parte I. 5.ed. Petrópolis: Vozes, 1995. 210 p.

JORGE, Maria Salete Bessa. Situações vivenciadas pelos alunos de enfermagem, durante o curso, no contexto universitário, apontadas como norteadoras de crise. Rev. Esc. Enf.USP. São Paulo, v.30, n. 1, p.138-48, abr. 1996.

LIMA, L.A.N. Capoeira angola - lição de vida na civilização brasileira. 1991. 142 p. Dissertação (Mestrado) - Pontifícia Universitária Católica de São Paulo, São Paulo.

MARTINS, Joel; BICUDO, Maria Aparecida Viggiani. A pesquisa qualitativa em psicologia: fundamentos e recursos básicos. São Paulo: Moraes, 1989. 110 p.

SADALA, Maria Lúcia Araújo. Estudo da ansiedade como variável no relacionamento aluno-paciente. Rev. latino-am. Enfermagem, Ribeirão Preto, v.2, n.2, p.21-35. jan. 1994.

SCHMARCZEK, Marilene. Ansiedade- estado em situações de sala de aula e estágios de enfermagem. Rev. latino-am. Enfermagem, Ribeirão Preto, v.5, n.2, p.305-325, jul. 1984 